\title{
Small vessel vasculitis presenting as neurological disorder
}

\author{
DH MILLER, LF HAAS, C TEAGUE, ${ }^{*}$ TJ NEALE $\dagger$ \\ From the Departments of Neurology, Renal Medicine $\dagger$ and Pathology, ${ }^{*}$ Wellington Hospital, Wellington, \\ New Zealand
}

SUMMARY Three patients with skin or muscle biopsy evidence of small vessel vasculitis presented with neurological symptoms: (1) frequent transient ischaemic attacks, (2) myalgia with encephalopathy, and (3) myalgia with marked weakness. The diagnosis of small vessel vasculitis needs consideration especially if presentation with polyneuropathy or cutaneous involvement is associated with elevation of ESR or serum immunoglobulins. Neurological illness may be a more common presentation of small vessel vasculitis than previously recognised.

The vasculitides are a group of overlapping conditions that can be classified according to the size of vessel involved. Giant cell arteritis involves large arteries, polyarteritis nodosa mainly medium sized muscular arteries and small vessel vasculitis affects the post-capillary venule most commonly. Capillaries and arterioles are involved less frequently. Mononuclear cells or polymorphonuclear leucocytes may be the predominant cell type in the perivascular and vascular infiltrate and leucocytoclasis - that is fragmentation of neutrophils-is sometimes observed. The skin is the most common organ involved. When small vessel vasculitis occurs in the setting of a known or suspected antigenic stimulus it has been referred to as hypersensitivity vasculitis. Virtually all the vasculitides may result from hypersensitivity to various antigens, though the term hypersensitivity vasculitis is usually applied to those with small vessel involvement. ${ }^{12}$ Nervous system involvement in small vessel vasculitis not associated with systemic lupus erythematosus is not well recognised. ${ }^{3}$ The following three patients with biopsy-proven small vessel vasculitis demonstrate that presentation can be with symptoms indicating central or peripheral nervous system involvement.

\section{Patient 1}

In 1966 when aged 34 years, a Caucasian male who had consumed large quantities of tobacco and alcohol over

\footnotetext{
Address for reprint requests: Dr DH Miller, The National Hospitals for Nervous Diseases, Queen Square, London, WC1N 3BG, UK
}

Received 4 January 1984.

Accepted 4 February 1984 many years first noticed an unsteady gait which lasted two weeks. Several similar events occurred over the next 10 years. In 1976 there were three episodes of transient right visual loss, in 1978 sudden weakness of the right arm lasting several hours and later that year, sudden left facial weakness, visual loss, ataxia and vomiting of one day's duration. From then until 1980 there were recurrent episodes of transient vertebrobasilar ischaemia. Examination then revealed mild gait ataxia and general hyperreflexia with flexor plantar responses. Cardiovascular examination was normal. He was normotensive.

Representative results of investigations performed during 1979 and 1980 were as follows: ESR 100, 72 and $85 \mathrm{~mm} / \mathrm{h}$; serum IgA $6.4 \mathrm{~g} / \mathrm{l}$ (normal $0 \cdot 8-3 \cdot 8$ ); IgG $11.1 \mathrm{~g} / \mathrm{l}$ (normal 6.6-14.0); IgM 2.03 g/l (normal 0.80-1.5); cerebrospinal fluid (CSF) showed no cells and a protein of 0.7 g/l (normal $<0.6 \mathrm{~g} / \mathrm{l}$ ) with $15 \%$ igG (normal $<10 \%$ ). Three oligoclonal bands were present in the CSF. The mid-stream urine showed no protein or casts. Renal biopsy demonstrated only non-specific thickening of the glomerular basement membrane by light and electron microscopy. Immunofluorescence stains for immunoglobulins and complement were negative. There was no evidence of lupus nephritis. Right lateral popliteal nerve motor conduction (fibular head to ankle) was $43 \mathrm{~m} / \mathrm{s}$. Right lateral popliteal nerve action potential ${ }^{4}$ and sural sensory potentials ${ }^{5}$ were absent. Electromyographic examination of the right tibialis anterior and small hand muscles was normal.

The following additional investigations were negative or normal; haemoglobin, white cell count and differential, antinuclear factor, anti-DNA antibodies, complement levels, fasting glucose and lipids, treponemal serology, serum and urine protein electrophoresis, hepatitis B surface antigen and antibody, cryoglobulins, chest radiograph, ECG, echocardiogram, CT head scan, arch aortogram, bilateral vertebral and carotid arteriograms, and biopsies of the left gastrocnemius and left deltoid muscles and of the left temporal artery.

In October 1981 a further episode of vertigo occurred 


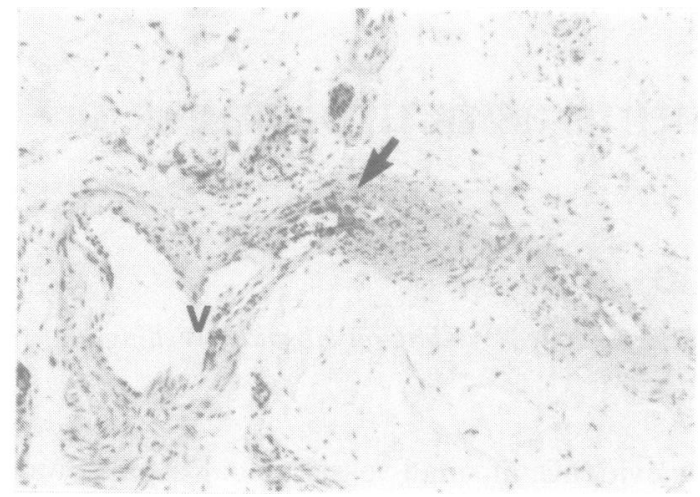

Fig 1 Photomicrograph taken from the biopsy of a purpuric skin lesion in patient 1. It shows a small dermal vein $(V)$, the wall of which contains a focal area (arrow) of fibrinoid necrosis and polymorphonuclear cell infiltrate. (Haematoxylin and Eosin $\times 83$ ).

and the right ring finger suddenly became white and cold. ESR was $98 \mathrm{~mm} / \mathrm{h}$ and IgA $9.2 \mathrm{~g} / \mathrm{l}$. IgG immune complexes (assayed by polyethylene glycol precipitation) were measured at a level of $0.071 \mathrm{~g} / 1$ (normal $<0.03 \mathrm{~g} / \mathrm{l}$ ). Cryoglobulins were not detected. Palpable purpuric lesions had appeared on the feet. Biopsy of one such lesion demonstrated active necrotising vasculitis affecting small vessels (see fig 1). Immunoperoxidase stain for IgM showed this immunoglobulin within vessel walls. Treatment was commenced with prednisone $80 \mathrm{mg}$ and cyclophosphamide 50 mg daily. Cyclophosphamide was stopped after eight weeks and the prednisone slowly withdrawn. Six months later the patient's feet became gangrenous; lower limb arteriography revealed bilateral femoropopliteal occlusions. The patient required bilateral below knee amputations. In May 1983 there was a further vertebrobasilar vascular event with recovery over two weeks. The ESR at this time was $47 \mathrm{~mm} / \mathrm{h}$.

\section{Patient 2}

In November 1980 a 26-year-old Polynesian male became ill over 24 hours, with muscle aches, arthralgia, cough, chills, fever, vomiting, abdominal pain and right iliac fossa tenderness. Appendicectomy was performed. The appendix showed mild acute appendicitis with prominent perivascular lymphocytic cuffing. A generalised convulsion occurred on the third postoperative day. At this time neurological examination and routine investigations were normal except for an ESR of $78 \mathrm{~mm} / \mathrm{h}$.

Repeated generalised convulsions followed and fever persisted. Over the next three weeks thiopentone infusion was required to maintain seizure control. Results of investigations included the following: antinuclear factor positive to 1 in 10; anti-double stranded DNA antibodies negative; serum IgG $18.7 \mathrm{~g} / 1$ (normal <14); serum IgA, IgM were normal as were complement levels. Serology indicated that there had been no recent herpes simplex infection. EEG showed non-specific diffuse rhythmic and spontaneous slow wave activity. Bilateral carotid arteriography was normal. CSF contained no cells, a protein concentration of $0.35 \mathrm{~g} / \mathrm{l}$ and a marked increase in the IgG fraction (28\%; upper limit normal $11 \%$ ). Oligoclonal bands were not present. CT scan was initially normal but displayed loss of the grey-white matter interface when repeated one month later. This was especially prominent in the frontal and temporal lobes. One month after the onset of the illness, limb areflexia was noted as a new finding. Nerve conduction studies were not performed. ESR remained high ranging between 95 and $120 \mathrm{~mm} / \mathrm{h}$. Skin and muscle (deltoid) biopsies showed a perivascular lymphocytic infiltrate around small vessels particularly capillaries. There was no necrosis or leucocytoclasis. Treatment was commenced with prednisone $60 \mathrm{mg}$ and cyclophosphamide $150 \mathrm{mg}$ daily. After eight weeks, cyclophosphamide was discontinued and prednisone slowly withdrawn. Fever settled, seizures became less frequent and the ESR fell to $25 \mathrm{~mm} / \mathrm{h}$. The patient has been left with major intellectual impairment and frequent seizures.

\section{Patient 3}

A previously healthy 15-year-old male was admitted in 1983 with muscle pain, weakness and mild renal failure. Sore throat had been present three weeks earlier and infected burns on one hand occurred two months prior to admission. Both improved without specific treatment. Nausea, vomiting, headache and facial swelling began two weeks prior to admission and nine days later his arms, shoulders and legs became painful. Within two days pain had intensified and there was fever $\left(39^{\circ}-40^{\circ} \mathrm{C}\right)$ and profound debilitating weakness, more than could be accounted for by pain alone. He was unable to walk. The urine became dark and frothy. Examination revealed an extremely ill patient with fever and tachycardia. There was generalised symmetrical weakness of all limb muscles, more marked proximally, with prominent muscle tenderness and swelling. Truncal weakness was marked. Deep tendon reflexes were depressed and plantar responses flexor. There was clinical evidence of hypervolaemia. His blood pressure was $160 / 80$. Investigations included: haemoglobin $12.8 \mathrm{~g} / \mathrm{l}$; white cell count $27.6 \times 10^{9} / 1$ (neutrophils $80 \%$, lymphocytes $3 \%$, monocytes $6 \%$ ); ESR 55 $\mathrm{mm} / \mathrm{h}$, serum potassium $5.8 \mathrm{mmol} / \mathrm{l}$ (normal $3 \cdot 5-5 \cdot 2$ ); serum creatinine $0.156 \mathrm{mmol} / \mathrm{l}$ (normal $0.071-0.122$ ); total protein $68 \mathrm{~g} / \mathrm{l}$ (normal 66-83); albumin $19 \mathrm{~g} / \mathrm{l}$ (normal $38-48$ ); alanine aminotransferase $67 \mathrm{U} / \mathrm{l}$ (normal 12-48). Other liver function tests were normal. Serum IgG $19.5 \mathrm{~g} / 1$ (normal 6.6-14.0); IgA 1.5 g/l (normal 0.8-3.8); IgM 0.79 g/l (normal 0.8-1.4); serum complement levels: total complement 72 units (normal 40-150); C3 $0.54 \mathrm{~g} / 1$ (normal $0 \cdot 8-1 \cdot 4$ ); C4 $0 \cdot 18 \mathrm{~g} / \mathrm{l}$ (normal $0 \cdot 2-0 \cdot 8$ ). ASO titre 833 units (normal 250); antihyaluronidase titre 2048 (normal $<256$ ); anti-DNAase B, 340 units (normal <340). Urinalysis showed $2+$ protein and $1+$ blood. The urine sediment contained moderate numbers of red cells and a few pigmented coarsely granular casts. Spectrophotometric analysis of the urine indicated trace amounts of myoglobin. The following investigations were normal: antinuclear factor, anti-DNA antibodies, rheumatoid screen, antiskeletal muscle antibodies, circulating IgG-containing immune complexes. Serum creatine kinase (CK) values were 60,46 and $39 \mathrm{u} / \mathrm{l}$ (normal 64-330). Right lateral popliteal motor 


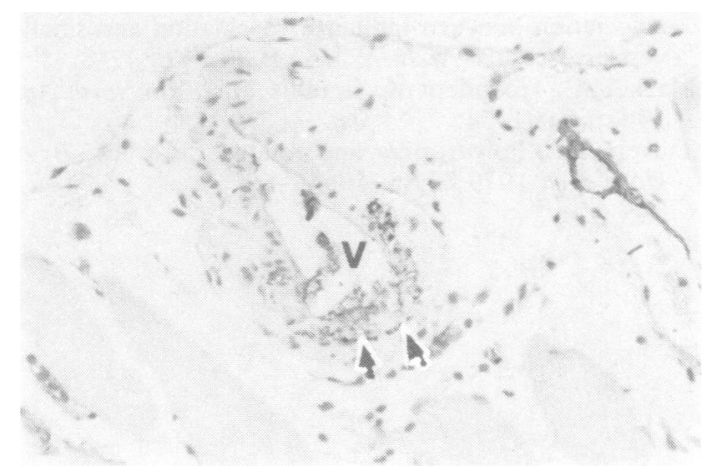

Fig 2 Photomicrograph of a small vein $(V)$ present in the deltoid muscle biopsy of patient 3. It shows a cellular infiltrate in the wall of the vessel together with darkly staining deposits containing the third component of complement (arrows). ( $\mathrm{C}_{3}$ immunoperoxidase stain $\left.\times 270\right)$.

nerve conduction velocity was $50 \mathrm{~m} / \mathrm{s}$. Right lateral popliteal nerve action potential was absent and sural sensory action potential of reduced amplitude $(5.0 \mu \mathrm{v}$ peak to peak). Electromyography four and seven days after the onset of weakness showed prolonged complex polyphasic units up to 30 milliseconds duration in the right deltoid, left tibialis anterior and vastus medialis muscles. Neither spontaneous activity nor amplitude abnormality was present. Myopathic potentials were not seen. Muscle biopsy (left deltoid) showed a hypersensitivity (leucocytoclastic) vasculitis affecting small vessels (fig 2). Histological evidence of muscle degeneration, regeneration or atrophy was not present. Immunoperoxidase stains showed granular deposits of IgM, IgG and to a lesser extent, the third component of complement in small vessel walls.

The patient was treated with prednisone $100 \mathrm{mg} /$ day and with penicillin $250 \mathrm{mg}$ 6-hourly. Overnight there was loss of muscle tenderness, fever and tachycardia with dramatic improvement in muscle strength. Three weeks later he was symptom-free on prednisone $80 \mathrm{mg} /$ day and the ESR had fallen to $4 \mathrm{~mm} / \mathrm{h}$. Subsequent progress has been uneventful except for a recurrence of symptoms within one day of inadvertent sudden cessation of prednisone three weeks after the initiation of treatment. The symptoms reversed immediately on reintroduction of the prednisone. At the time of writing three months after starting prednisone, he is well, taking $20 \mathrm{mg}$ daily. ESR is $3 \mathrm{~mm} / \mathrm{h}$.

\section{Discussion}

In contrast to giant cell arteritis and polyarteritis nodosa, neurological involvement with small vessel vasculitis not associated with systemic lupus erythematosus has not been commonly recognised. In one study of thirty-eight patients with cutaneous vasculitis $^{6}$ three had peripheral neuropathy, two mononeuritis multiplex, two a stroke syndrome and one headache, diplopia and dysphagia. It has also been described with essential mixed cryoglo- bulinaemia. ${ }^{7}$ When small vessel vasculitis occurs the presentation is usually, though not invariably, with skin purpura. Fever and myalgia which were prominent in two of our cases has been recorded by others ${ }^{8-10}$ but has not been emphasised as we believe it should. The type of large vessel disease in the first patient was not determined. It was probable that it was atherosclerotic and unrelated to the small vessel vasculitis. A causative antigen in small vessel vasculitis is not always found. The serological results in the third patient suggest the illness followed a streptococcal infection of either the pharynx or the hand burn. If the prolonged polyphasic units are taken to be part of the disease then the earlier infected hand burn rather than the pharyngitis would seem to be the likely antigenic stimulus. This is supported by the antihyaluronidase titre which typically reflects skin infection. The relevance of the weakly positive spectrophotometric test for myoglobin in the urine in the presence of normal CK plasma results, despite marked muscle symptoms, is unclear.

In the first two cases where central nervous system symptoms occurred it was assumed that the pathological changes demonstrated also occurred centrally. Accepting this inference the following conclusions regarding small vessel vasculitis are made: (1) the nervous system may be involved at presentation, (2) there may be a short or long history of neurological involvement in the absence of prominent multisystem disease, (3) cutaneous involvement need not be present, (4) myalgia may be a prominent symptom, (5) neuropathy may be present even if symptomless, (6) the percentage of IgG of total CSF protein may be elevated in such patients. Small vessel vasculitis should be considered as a pathological diagnosis in patients presenting with neurologic syndromes.

\section{References}

' Fauci AS, Haynes BF, Katz P. The spectrum of vasculitis: clinical, pathologic, immunologic and therapeutic considerations. Ann Int Med 1978;89:660-76.

${ }^{2}$ Cupps TR, Springer RM, Fauci AS. Chronic, recurrent small-vessel cutaneous vasculitis. Clinical experience in 13 patients. JAMA 1982;247:1994-8.

${ }^{3}$ Moore PM, Cupps TR. Neurological complications of vasculitis. Ann Neurol 1983;14:155-67.

${ }^{4}$ Gilliatt RW, Goodman HV, Willison RG. The recording of lateral popliteal nerve action potentials in man. $J$ Neurol Neurosurg Psychiatry 1961;24:305-18.

5 Guiloff RJ, Sherratt RM. Sensory conduction in medial plantar nerve. Normal values, clinical applications and a comparison with the sural and upper limb sensory nerve action potentials in peripheral neuropathy. $J$ Neurol Neurosurg Psychiatry 1977;40:1168-81. 
- Winkleman RK, Ditto WB. Cutaneous and visceral syndromes of necrotizing or "allergic" angiitis. Study of 38 cases. Medicine 1964;43:59-89.

${ }^{7}$ Cream JJ, Hern JEC, Hughes RAC, MacKenzie ICK. Mixed or immune complex cryoglobulinaemia and neuropathy. J Neurol Neurosurg Psychiatry 1974;37:82-7.
${ }^{8}$ Blumberg S, Bienfang D, Kantrowitz FG. A possible association between influenza vaccination and smallvessel vasculitis. Arch Int Med 1980;140:847-8.

${ }^{9}$ Mackel SE. Treatment of vasculitis. Med Clin North Am 1982;66:941-54.

${ }^{10}$ Travers RL. Polyarteritis and related disorders. $B r J$ Hosp Med 1979;22:38, 40, 42-6. 